\title{
СОАВТОРСТВО И СОВМЕСТНОЕ ОБЛАДАНИЕ ИСКЛЮЧИТЕЛЬНЫМ ПРАВОМ
}

\author{
Линейцев Евгений Анатольевич \\ Аспирант, ФГБОУ ВО «Байкальский государственный \\ университет", г. Иркутск \\ e.lineytsev@mail.ru
}

\section{CO-AUTHORSHIP AND JOINT OWNERSHIP OF THE EXCLUSIVE RIGHT}

\section{E. Linetsev}

Summary. In modern times, interest in copyright and the results of intellectual activity has increased both on the part of the state and society. The object of copyright represents not only property, but also cultural value. Due to the increase in the turnover of the results of intellectual activity in the modern economy, an increasing number of people are attracted to create high-quality and complex works.

Thus, for a clear understanding of the legal status of persons who participated in the creation of the object of copyright by joint work, the author of this article considers it necessary to determine who are the coauthors of the work; types of co-authorship; the relationship between the concepts of the author and the copyright holder; differences in legal regulation between co-authors and persons who have exclusive rights, but are not the authors of the work, as well as to identify the problems of joint ownership of the exclusive right, complicated by the multiplicity of persons.

Keywords: exclusive right, intellectual property, co-authorship regime, joint creativity, share in exclusive right.
B Гражданском законодательстве предусмотрено, что, если произведение создано совместно несколькими лицами, они признаются соавторами, вне зависимости от того, является ли произведение неразрывно целым или части которого имеют самостоятельное значение. При этом в пункте 1 статьи 1229 Гражданского Кодекса Российской Федерации (далее - ГК РФ) указано, что автором может быть только лицо, принимавшее личное творческое участие в создании произведения.

Таким образом, существуют два условия, чтобы быть соавтором: наличие творческого труда, которое проявляется в выражении личности авторов в своем произве- дении, наличии уникального авторского стиля, индивидуальности; а также его совместность.

На практике же иногда возникает вопрос, имеет ли место соавторство при объединении отдельных самостоятельных произведений, созданных разными авторами. Мы считаем, что самостоятельные части будут составлять произведение, созданное в соавторстве, только в случае объединения этих частей единством целей, идей авторов.

Также стоит отметить, что законодательно не определен объем и степень участия соавторов при создании объекта авторского права. Вследствие нематериально- 
го характера объекта авторский прав, не всегда удается с точностью определить вклад каждого из авторов в ту или иную часть произведения. Таким образом, лицо, внесшее даже незначительный вклад, обладает таким же объемом прав, как и другие авторы, в том числе и правом на вознаграждение [1, с. 40].

По своему характеру соавторство, в зависимости от автономности частей произведения, может быть:

1. раздельным (автор части произведения, которая может быть использована самостоятельно, отдельно от основного произведения, использует ее по своему усмотрению).

2. неделимым (использование произведение осуществляется совместно, но при этом ни один из авторов не может запрещать использование произведение без наличия веских причин).

Поэтому в соответствии со статьей 1258 ГК РФ в отношении одного результата интеллектуальной деятельности автор самостоятельных частей осуществляет использование по своему усмотрению, а в отношение остального произведения - совместно с другим автором.

В силу данной двойственности соавторства законодателем указывается на возможность регулирования отношений между авторами посредством заключения соглашения, которое на практике заключается крайне редко. Поэтому авторам следует проявлять большую осторожность при определении круга авторского коллектива и при признании соавторами лиц, участвовавших в создании результата интеллектуальной деятельности.

Таким образом, при отсутствии между авторами соглашения, можно сделать вывод, что:

- вопросы о распоряжении исключительным право соавторами осуществляется совместно и единогласно при нераздельном соавторстве, в отношении раздельного соавторства — по своему усмотрению.

- все доходы, полученные от использования результата совместной деятельности, распределяются поровну [2, с. 13].

Стоит отметить, что основные проблемы проявляются, когда обладателями исключительного права на один и тот же объект авторского права наравне с соавторами являются иные лица. Исключительное право на произведение отчуждаемо, таким образом оно может переходить от автора к другим лицам. В отличие от статуса автора, статус правообладателя содержит в себе только исключительное право. Он возникает с момента приобретения исключительного права и утрачивается вместе с ним. Правообладателем не может являться лицо, которое приобрело исключительное право по лицензионному договору, так как данный договор имеет срочный характер, и право передается в усеченном виде. В отличие от автора, правообладатель может быть, как физическим, так и юридическим лицом, как российским, так и иностранным.

В доктрине упоминается деление правообладателей на первичных и производных, данное деление построено на критерии наличия прав предшественника. Первичными правообладателями, являются лица, создавшие произведение, то есть получившие исключительное право в силу факта создания. По российскому законодательству в роли первичных правообладателей выступают авторы. Производными считаются лица, приобретшие исключительное право не в силу создания произведения, а по иным основаниям.

Таким образом, стоит отметить отличия в правовом положении соавторов и обладателей исключительного права, не являющихся соавторами.

1. Возможность обращения взыскания на принадлежащее исключительное право. Статьей 1284 ГКРФ предусмотрено, что на исключительное право, принадлежащее автору произведение, не допускается обращение взыскания, за исключением случаев, когда исключительное право на данное произведение является предметом договора залога. На исключительное право, принадлежащее иным лицам, а также по лицензионному договору обращение взыскания допускается.

2. Преимущественное право соавтора на приобретение права использования произведения лицензиата в случае реализации данного права с публичных торгов при процедуре обращения взыскания (пункт 2 статьи 1284 ГК РФ);

3. В соответствии с пунктом 2 статьи 1283 ГК РФ в случае смерти одного из соавторов исключительное право при раздельном соавторстве -прекращается в части принадлежащего ему права, при неразрывном соавторстве - доля умершего соавтора в исключительном праве переходит ко всем пережившим соавторам в равных долях, при этом, исключительное право должно быть признано выморочным имуществом;

4. Режим использования произведения. Ранее уже упоминалось, что соавторы совместно пользуются исключительным правом при нераздельном соавторстве. Но, в отличие от первых, на производных правообладателей не распространяются положения статьи 1258 ГК РФ, таким образом, при совместном обладании исключительным правом на произведение одновременно автора и неавтора, для последнего не требуется получать 
согласие на использование. В итоге, действия одного из обладателей исключительного права могут повлиять на интересы других правообладателей - авторов произведения. На основании изложенного, мы считаем необходимым законодательно закрепить, что при совместном обладании исключительным правом на произведение одновременно автора и неавтора, следует применять положения о соавторстве, вне зависимости от личности обладателя исключительного права.

5. Ограничение ответственности соавтора произведения по лицензионному договору, договору об отчуждении исключительного права только суммой реального ущерба.

6. Пункт 2 статьи 1295 ГК РФ говорит, что исключительное право подлежит возврату работнику - автору произведения, если правооблада- тель в течение трех лет с момента передачи прав никак не использовал или не распорядился им [3, c. 278].

На основании изложенного можно сделать вывод, что в современном гражданском законодательстве преследуется концепция защиты прав слабой стороны, в данных правоотношениях слабой стороной, по мнению законодателя, является автор произведения. Приоритет со стороны государства в данной ситуации получает не производный правообладатель, который приобрел исключительное право не в силу создания произведения, а по иным основаниям, а автор результата интеллектуальной деятельности, обладающий неразрывной связью и личной природой с произведением, несмотря на то, что исключительное право является имущественным и отчуждаемым.

\section{ЛИТЕРАТУРА}

1. Калятин В.О. Проблемы определения системы правообладателей результатов интеллектуальной деятельности // ИС. Авторское право и смежные права. 2020. N8. C. 35-48.

2. Ульбашев А.Х. Соавторы как субъекты авторского права // Гражданское право. 2020. N4. С. 11-14.

3. Мартьянова Е.Ю. Гражданско-правовое положение сообладателя исключительного авторского права // Вестник Пермского университета. Юридические науки. 2020. N2. С. 274-289.

(с) Линейцев Евгений Анатольевич ( e.lineytsev@mail.ru ).

Журнал «Современная наука: актуальные проблемы теории и практики»

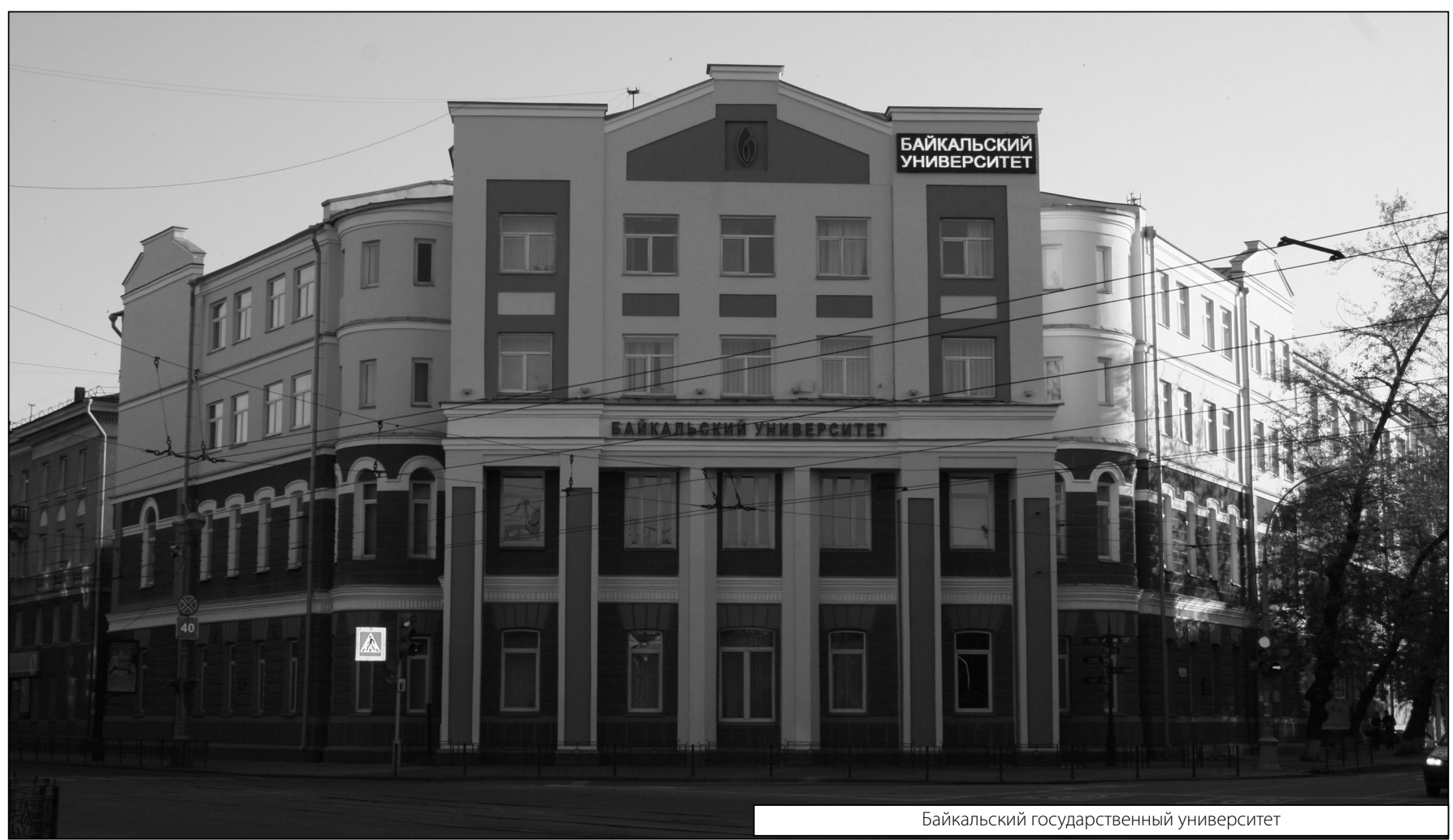

